\title{
Pengaruh Noise Proses (Q) dan Noise Pengukuran (R) di Kalman Filter Yang Diaplikasikan Pada Hasil Pembacaan Sensor Suhu DHT11 dan LM35
}

\author{
Vera Firmansyah ${ }^{1}$ \\ D3 Metrologi dan Instrumentasi, \\ Akademi Metrologi dan Instrumentasi, Kementerian Perdagangan, \\ Cihanjuang - Bandung \\ e-mail: vera.firmansyah@kemendag.go.id
}

\begin{abstract}
ABSTRAK
Noise atau gangguan merupakan parameter yang selalu muncul dalam setiap proses akuisisi data dari sebuah sensor. Pada makalah ini sensor yang digunakan adalah sensor suhu jenis DHT11 atau LM35 yang dipasangkan pada arduino mega untuk memantau suhu ruangan laboratorium massa yang telah mendapatkan ISO 17025. Data pencilan yang muncul secara tiba-tiba dapat dihilangkan atau dikurangi. Salah satu teknik yang paling sederhana dalam mengurangi noise yaitu merata-ratakan dalam selang waktu tertentu atau jumlah data tertentu sebelum ditampilkan. Makalah ini memperlihatkan proses menghilangkan noise dengan bantuan Kalman Filter agar data yang ditampilkan lebih bersih dari noise. Keberhasilan Kalman Filter dalam menghilangkan noise ditentukan oleh nilai $\mathrm{R}$ yang disebut kovarian noise pengukuran dan Q yang disebut kovarian noise proses. Pemiihan nilai R dan Q yang tepat dapat menentukan keberhasilan Kalman Filter dalam menghilangkan noise. Kalman Filter diaplikasikan pada sensor suhu dengan keluaran berupa tegangan jenis LM35 dan sensor suhu keluaran berupa temperature jenis DHT11 dengan bantuan library yang disediakan. Dapat disimpulkan bahwa Kalman Filter dapat mengurangi noise yang muncul dari sensor. Pemilihan nilai R dan Q juga dapat meningkatkan performa Kalman Filter. Semakin kecil nilai R dan Q maka performa Kalman Filter semakin baik. Nilai R=1e-5 dan $\mathrm{Q}=1$ e-8 memberikan hasil yang paling baik untuk sensor suhu jenis DHT11 dan LM35.
\end{abstract}

\section{Kata kunci: Sensor Suhu, LM35, DHT11, Kalman Filter, Arduino}

\section{ABSTRACT}

Noise or interference is a parameter that always appears in every data acquisition process from a sensor. In this paper the sensor used is a temperature sensor type DHT11 or LM35 which is attached to Arduino Mega to monitor the temperature of the mass laboratory room that has received ISO 17025. Outliers data that appears suddenly can be removed or reduced. One of the simplest techniques in reducing noise is averaging over a certain time interval or a certain amount of data before being displayed. This paper shows the process of removing noise with the help of Kalman Filter so that the data displayed is cleaner than noise. The success of the Kalman Filter in removing noise is determined by an $\mathrm{R}$ value called covariance noise measurement and $\mathrm{Q}$ which is called process noise covariance. The selection of the right $\mathrm{R}$ and $\mathrm{Q}$ values can determine the success of the Kalman Filter in removing noise. Kalman Filter is applied to the temperature sensor with output in the form of LM35 type voltage and output temperature sensor in the form of temperature type DHT11 with the help of the library provided. It can be concluded that Kalman Filter can reduce the noise that arises from the sensor. The selection of $\mathrm{R}$ and $\mathrm{Q}$ values can also improve the performance of the Kalman Filter. The smaller the R and Q values, the better the Kalman Filter's performance. $\mathrm{R}=1 \mathrm{e}-5$ and $\mathrm{Q}=1 \mathrm{e}-8$ give the best results for the temperature sensor types DHT11 and LM35.

Keywords: Temperature Sensor, LM35, DHT11, Kalman Filter, Arduino

\section{PENDAHULUAN}

Noise atau gangguan merupakan parameter yang selalu muncul dalam setiap proses akuisisi data dari sebuah sensor. Pada makalah ini sensor yang digunakan adalah sensor suhu jenis DHT11 dan LM35 yang dipasangkan pada arduino mega untuk memantau dan atau mengontrol suhu ruangan 
laboratorium massa yang telah mendapatkan ISO 17025. Kalman Filter (KF) merupakan salah satu filter yang dapat membantu menghilangkan atau mengurangi noise tersebut [4]. KF yang digunakan dalam makalah ini adalah jenis KF diskrit, dimana data yang muncul cenderung linier.

Dalam KF terdapat 2 (dua) buah parameter yang harus ditentukan di awal ketika sebuah data akan dimasukkan ke dalam KF, yaitu : noise proses $(\mathrm{Q})$ dan noise pengukuran $(\mathrm{R})$. Pada makalah ini akan diperlihatkan nilai kedua buah parameter tersebut yang cocok dengan karakter sensor suhu, baik itu sensor DHT11 ataupun LM35. Dengan mengetahui lebih awal tentang kedua parameter tersebut, akan menyebabkan KF bekerja lebih optimal.

\section{METODE}

\subsection{Kalman Filter Diskrit}

Pada tahun 1960 Kalman mempublikasikan makalah yang menjelaskan persoalan filter linier data diskrit [4]. Kalman Filter dapat memperkirakan keadaan suatu proses dengan cara meminimalisasi rata-rata eror kuadrat (mean square error) baik keadaan sebelumnya, saat ini, dan yang akan datang. Kalman Filter mengestimasi satu proses melalui mekanisme kontrol umpan-balik, filter mengestimasi keadaan dari proses kemudian mendapat umpan balik berupa nilai hasil pengukuran yang bercampur noise. Persamaan untuk Kalman filter dikelompokkan dalam dua bagian, persamaan update waktu dan persamaan update pengukuran. Persamaan update waktu bertugas untuk mendapatkan nilai pra-estimasi untuk waktu langkah selanjutnya. Persamaan update pengukuran bertugas untuk keperluan umpan balik, seperti memadukan hasil pengukuran terbaru dengan nilai praestimasi untuk mendapatkan nilai pascaestimasi yang lebih baik. Persamaan update waktu memprediksi nilai keadaan dan estimasi kovarian dari waktu langkah k-1 menuju k. Persamaannya dapat dilihat di bawah ini

$$
\begin{aligned}
& \hat{x}_{k}^{-}=A \hat{x}_{k-1}+B u_{k-1} \\
& P_{k}^{-}=A P_{k-1} A^{T}+Q
\end{aligned}
$$

Sedangkan untuk persamaan update pengukuran, langkah awal yang harus ditentukan adalah Kalman Gain $\left(K_{k}\right)$, nilai proses actual $\left(\hat{x}_{k}\right)$ untuk menghitung pasca estimasi keadaan dengan melibatkan nilai hasil pengukuran, dan terakhir adalah menghitung pasca estimasi kovarian eror $\left(P_{k}\right)$. Persamaannya dapat dilihat di bawah ini

$$
\begin{gathered}
K_{k}=P_{k}^{-} H^{T}\left(H P_{k}^{-} H^{T}+R\right)^{-1} \\
\hat{x}_{k}=\hat{x}_{k}^{-}+K\left(z_{k}-H \hat{x}_{k}^{-}\right) \\
P_{k}=\left(1-K_{k} H\right) P_{k}^{-}
\end{gathered}
$$

Persamaan update waktu dan update pengukuran merupakan siklus dari Kalman Filter. Ilustrasi dari kedua persamaan tersebut dapat dilihat pada Gambar 1. 


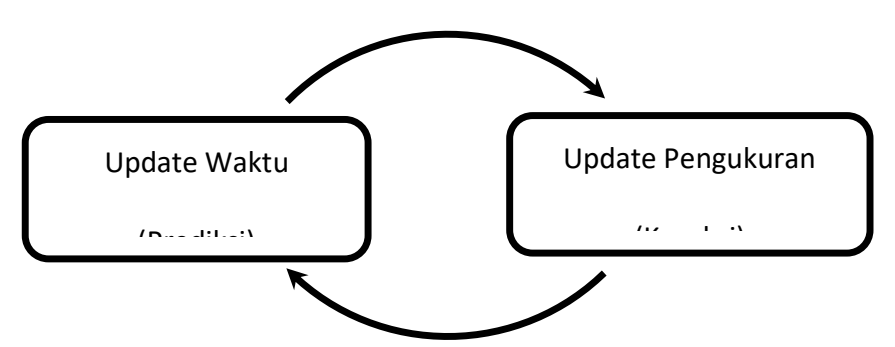

Gambar 1. Siklus Kalman Filter

\subsection{Perancangan Perangkat Keras}

Pada tulisan ini menggunakan Arduino Mega 2560 dan 2 (dua) buah sensor suhu, yaitu LM35 dan DHT11. Arduino Mega 2560 adalah mikrokontroller yang berbasis Arduino dengan menggunakan chip ATmega2560. Board ini memiliki pin I/O yang cukup banyak, sejumlah 54 buah digital $\mathrm{I} / \mathrm{O}$ pin dengan 15 pin PWM, 16 pin analog input, dan 4 pin UART (serial port hardware). Sensor yang digunakan adalah LM35 yang hanya dapat mengukur suhu. Keluaran sensor LM35 berupa sinyal analog berupa tegangan (V) yang akan dikonversikan terlebih dahulu ke suhu (T) sebelum di proses oleh Kalman Filter. LM35 memiliki akurasi yang cukup tinggi, impedansi yang rendah, dan linieritas yang tinggi. Sensor lainnya yang digunakan adalah jenis DHT11. Selain dapat mengukur suhu, sensor ini dapat pula mengukur kelembaban. Sensor DHT11 tidak memerlukan konversi dari sinyal analog karena sinyal keluaran dalam bentuk digital [1]. Sensor jenis DHT22 memiliki akurasi yang lebih baik dibandingkan dengan DHT11 yang dapat menampilkan 1 (satu) digit dibelakang koma [2]. DHT22 memiliki galat $4 \%$ lebih baik dibandingkan DHT11 [3]. Untuk itu penulis memilih DHT11 sebagai bahan perbandingan untuk menguji Kalman Filter yang akan dibandingkan dengan LM35, agar hasil yang didapat cukup signifikan perbedaannya.

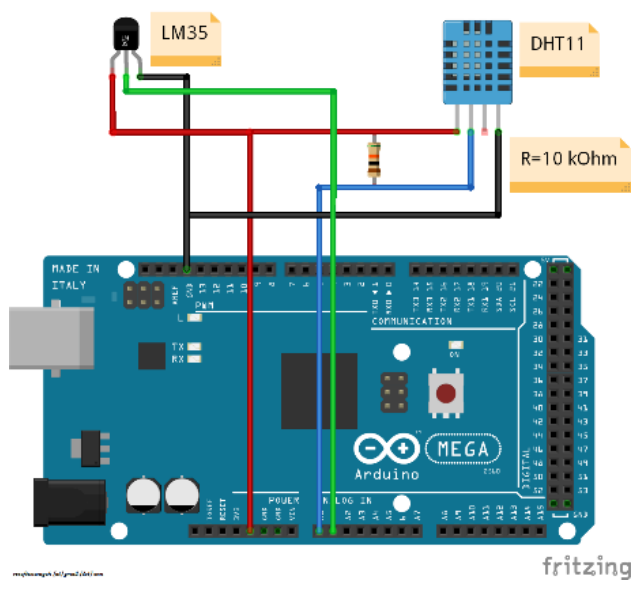

Gambar 2. Skema Perancangan Perangkat Keras Sensor Suhu di Arduino Mega 2560

Sensor LM35 terkoneksi di port A1 sedangkan sensor DHT11 terkoneksi di port A0 pada arduino mega.

\subsection{Perancangan Perangkat Lunak}

Bahasa pemrograman arduino adalah Bahasa $\mathrm{C}$ yang digunakan pada
AVR. Fungsi yang wajib ada pada arduino adalah setup dan loop. Fungsi setup akan dijalan 1 (satu) kali ketika arduino dijalankan, sedangkan fungsi loop dijalankan terus menerus. Selain kedua fungsi itu, kita bias membuat fungsi lainnya yang dapat dipanggil baik 
di dalam fungsi setup maupun fungsi loop. Pada tulisan ini secara garis besar kode yang digunakan dibagi menjadi 2 (dua) bagian, yaitu bagian mengambil data dari sensor dan bagian yang memproses data tersebut oleh Kalman Filter.

Implementasi Kalman Filter untuk sensor suhu yang akan disimpan di arduino dan proses dinyatakan dengan persamaan beda linier

$$
\begin{aligned}
& x_{k}=A x_{k-1}+B u_{k-1}+w_{k} \\
& x_{k}=x_{k-1}+w_{k}
\end{aligned}
$$

dengan pengukuran $z \in \mathfrak{R}^{1}$, yaitu

$$
\begin{aligned}
& z_{k}=H x_{k}+v_{k} \\
& z_{k}=x_{k}+v_{k}
\end{aligned}
$$

Keadaan $\mathrm{x}$ tidak berubah dari satu langkah ke langkah berikutnya $(\mathrm{A}=1)$, tidak ada input kontrol $(\mathrm{u}=0)$, dan pengukuran yang bercampur noise langsung didapatkan dari keadaan $\mathrm{x}$ $(\mathrm{H}=1)$. Persamaan update waktu menjadi

$\hat{x}_{k}^{-}=\hat{x}_{k-1}$

$P_{k}^{-}=P_{k-1}+Q$

dan persamaan update pengukurannya menjadi

$K_{k}=P_{k}^{-}\left(P_{k}^{-}+R\right)^{-1}$

$\hat{x}_{k}=\hat{x}_{k}^{-}+K\left(z_{k}-\hat{x}_{k}^{-}\right)$

$$
P_{k}=\left(1-K_{k}\right) P_{k}^{-}
$$

Dengan menganggap varian noise proses sangat kecil (misal $Q=10^{-8}$ ) dan $\hat{x}_{k-1}=0$, berasumsi bahwa nilai sebenarnya dari nilai konstan acak tersebut terdistribusi normal. Dengan memilih $P_{0}=0$, berarti kita yakin bahwa nilai awal estimasi keadaan $\hat{x}_{0}=0$. Jika terdapat ketidakpastian pada nilai $\hat{x}_{0}$, maka bisa memilih $P_{0} \neq 0$ (misal $P_{0}=1$ ) dan filter pada akhirnya akan konvergen. Untuk kovarian noise pengukuran (misal $R=10^{-5}$ ) karena merupakan nilai varian eror sebenarnya.

Proses pengambilan data melalui port serial dengan bantuan software "PLCDAQ for excel" yang dapat diunduh secara gratis [5]. Data yang diambil setiap 1 (satu) kali proses yaitu antara 100 - 2700 data, dimana untuk setiap data ditetapkan selama 0,5 s. Diagram alir aplikasi Kalman Filter data sensor suhu di arduino mega dapat dilihat pada gambar di bawah ini. 


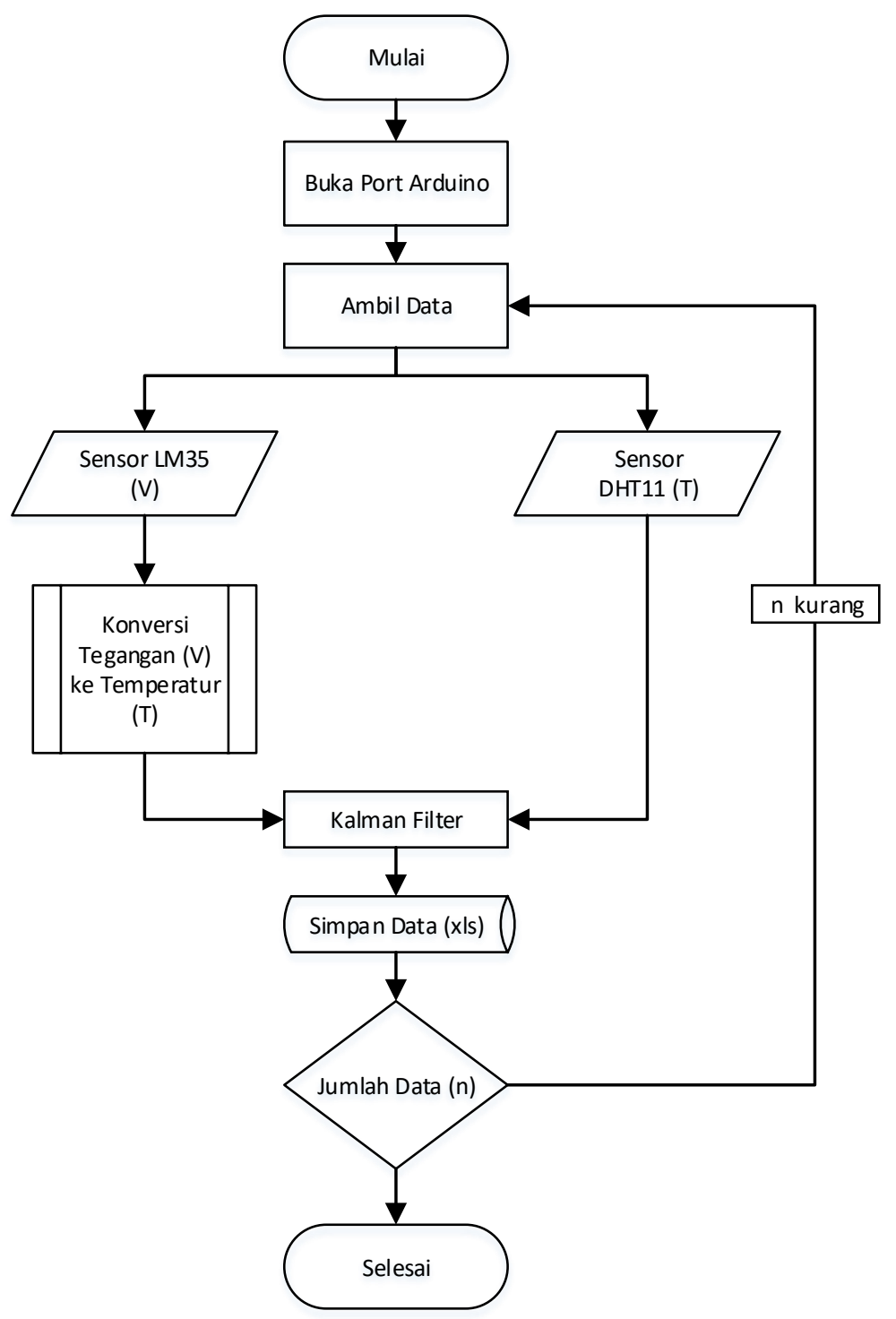

Gambar 3. Diagram Alir Aplikasi Kalman Filter Data Sensor Suhu di Arduino Mega

\section{PEMBAHASAN}

Pada table di bawah ini diperlihatkan kedua parameter tersebut dengan 3 (tiga) kombinasi. Pada gambar 7 diperlihatkan ketiga kombinasi tersebut yang diaplikasikan pada KF untuk sensor DHT11 yang dikondisikan konstan sebesar $25^{\circ} \mathrm{C}$.
Tabel 1. Nilai R dan Q pada Gambar 7 untuk Sensor DHT11

\begin{tabular}{|c|c|c|c|}
\hline No & Label & $\mathbf{R}$ & $\mathbf{Q}$ \\
\hline 1 & KF1 & $1 \mathrm{e}-5$ & $1 \mathrm{e}-8$ \\
\hline 2 & KF2 & $1 \mathrm{e}-1$ & $1 \mathrm{e}-2$ \\
\hline 3 & KF3 & $1 \mathrm{e}-0$ & $1 \mathrm{e}-2$ \\
\hline
\end{tabular}




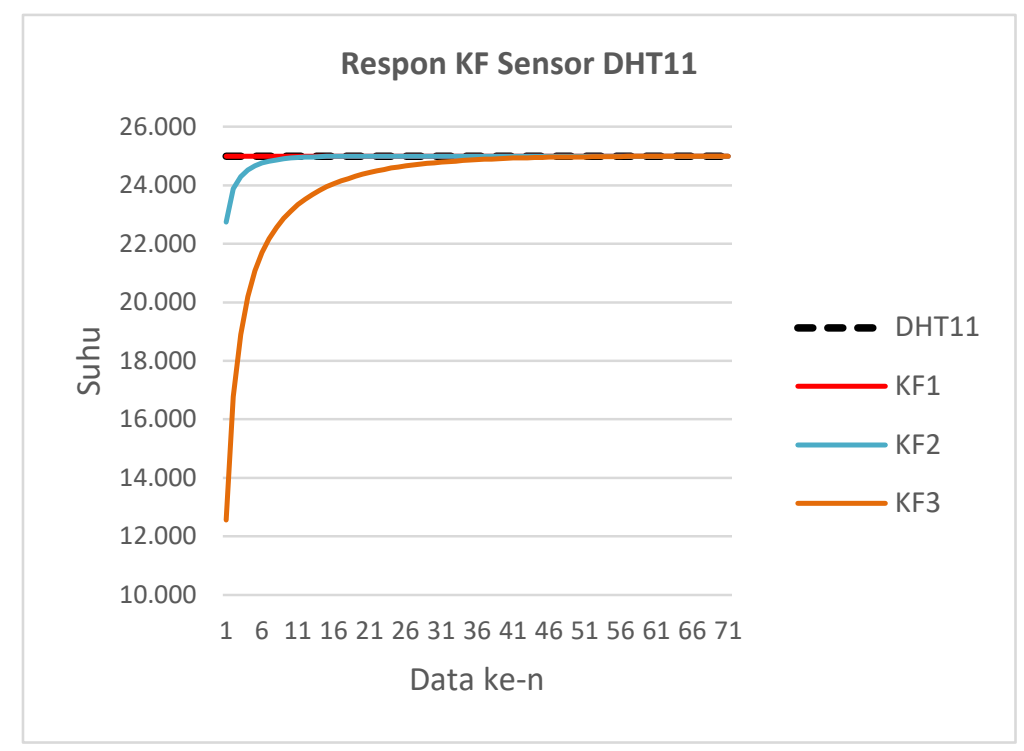

Gambar 4. Grafik Respon KF untuk Sensor DHT11

Dari ketiga kombinasi pada table 1 terlihat bahwa kedua parameter yang paling cocok dengan sensor DHT11 dengan suhu konstan yaitu grafik yang berwarna merah (KF1) dengan nilai $\mathrm{Q}=1 \mathrm{e}-8$ dan $\mathrm{R}=1 \mathrm{e}-5$. Untuk nilai suhu konstan, semakin kecil nilai $\mathrm{Q}$ dan $\mathrm{R}$, maka semakin mendekati nilai sebenarnya. Sedangkan pada KF2 dan KF3 yang memiliki nila $Q$ dan $\mathrm{R}$ lebih besar dibandingkan KF1 membutuhkan waktu agar hasil filter sama dengan data sebenarnya (sebelum di filter). Untuk sensor DHT11 dengan suhu tidak konstan, dapat dilihat pada gambar $5 \mathrm{di}$ bawah ini.

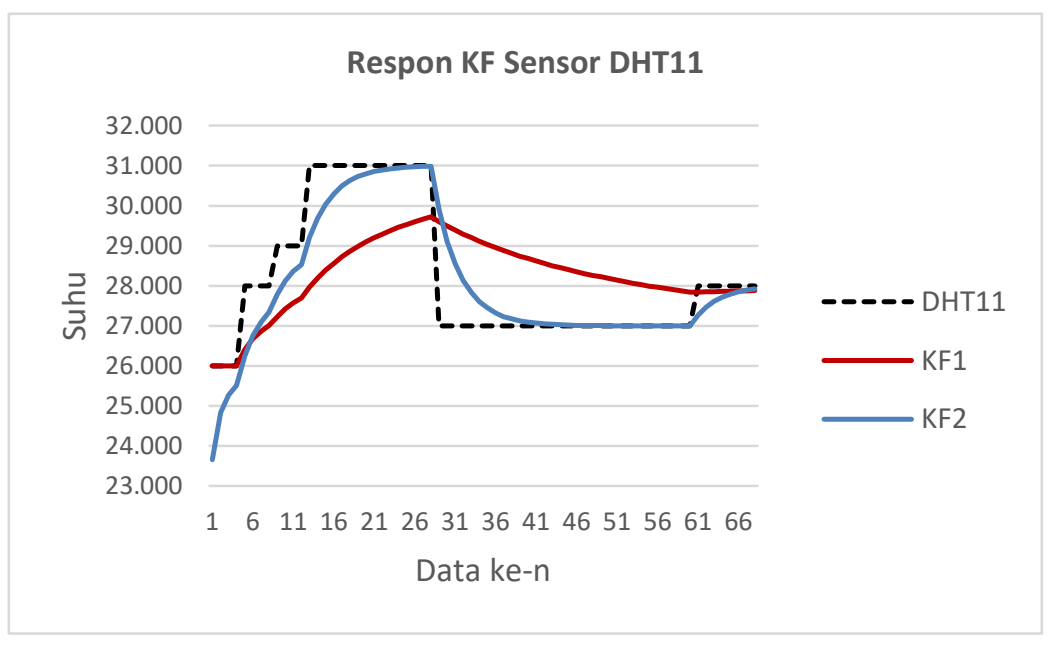

Gambar 5. Grafik Respon KF Pada Suhu Tidak Konstan untuk Sensor DHT11

Pada suhu tidak konstan, nilai $\mathrm{Q}$ dan $\mathrm{R}$ yang cocok adalah pada label KF1 (grafik warna merah). Hasil filter memperlihatkan bahwa nilainya tidak 
mudah terpengaruhi oleh perubahan data yang cukup cepat. Untuk sensor LM35 dengan suhu konstan, diperlihatkan pada gambar 6 di bawah ini. Untuk sensor
LM35 diberikan 3 (tiga) kombinasi kedua parameter $\mathrm{Q}$ dan $\mathrm{R}$ yang sama dengan sensor DHT11.

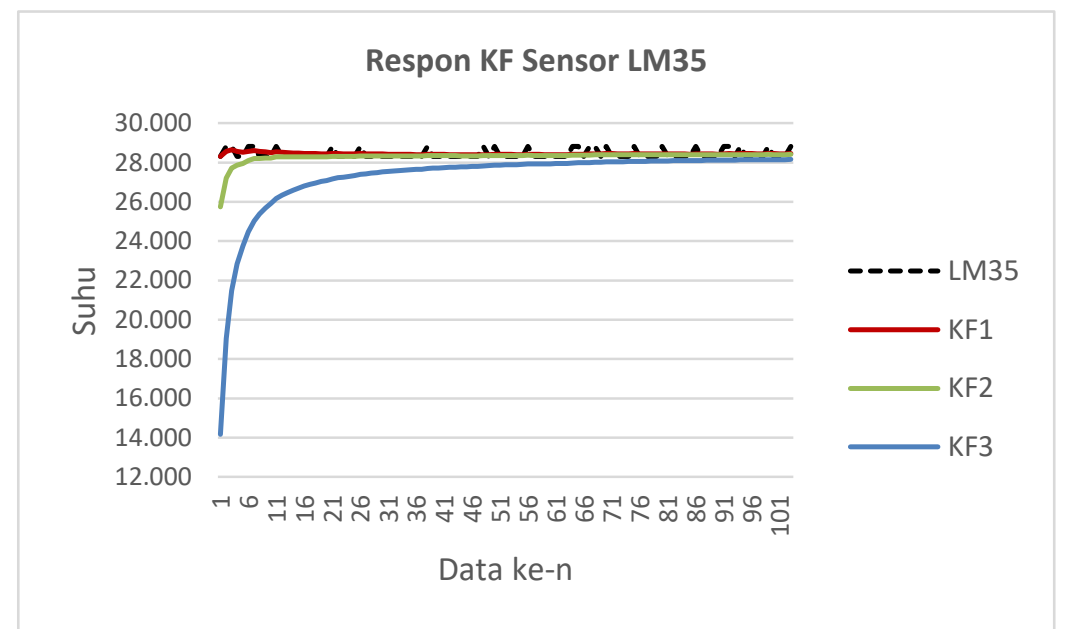

Gambar 6. Grafik Respon KF Pada Suhu Konstan untuk Sensor LM35

Gambar 6 memperlihatkan bahwa grafik KF1 memperlihatkan kencendrungan yang paling cepat menyesuaikan data hasil filter dengan data sebelum diberikan filter. Hal yang sama juga diperlihatkan pada 2 (dua) grafik lainnya yaitu KF2 dan KF3, dimana pada KF2 dan KF3 diberikan nilai parameter Q dan $\mathrm{R}$ yang lebih besar. Untuk data suhu sensor LM35 yang tidak konstan dapat dilihat pada gambar 7 .

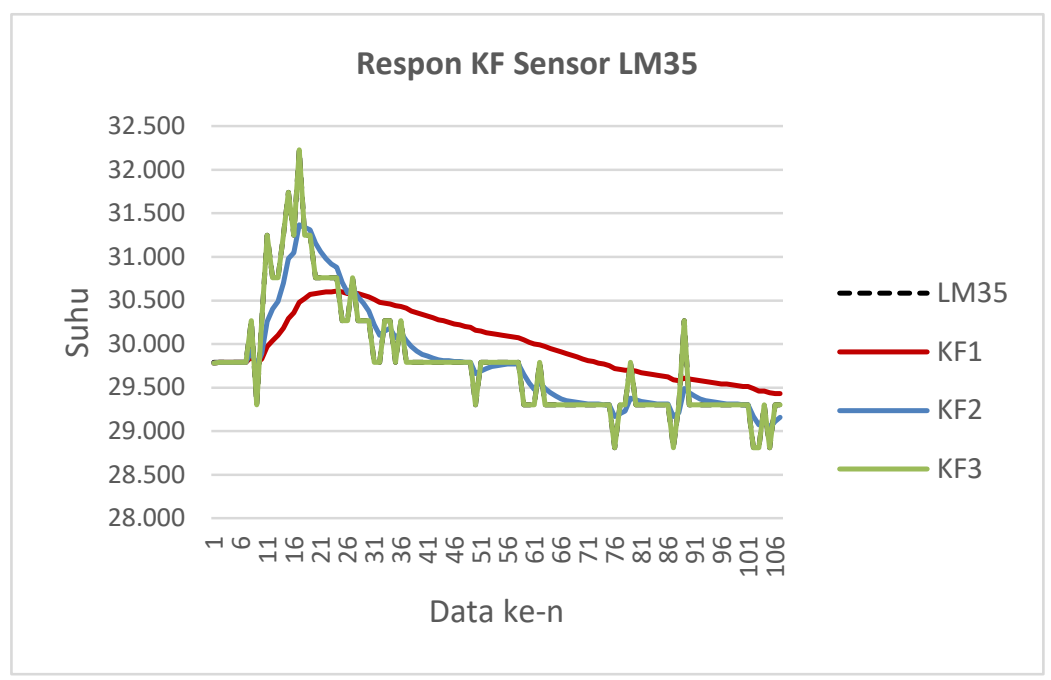

Gambar 7. Grafik Respon KF Pada Suhu Tidak Konstan untuk Sensor LM35 yang Diberikan Gangguan di Awal Pengukuran 
Gambar 7 memperlihatkan hal yang sama dengan sensor DHT11, dimana semakin kecil nilai $\mathrm{Q}$ dan $\mathrm{R}$ maka semakin memperlihatkan keberhasil $\mathrm{KF}$ dalam meminimalisasi noise.

\section{KESIMPULAN}

Diberikan 3 (tiga) buah kombinasi parameter $\mathrm{Q}$ dan $\mathrm{R}$ yang diterapkan pada sensor suhu jenis DHT11 dan LM35 yang memperlihatkan bahwa nilai $Q$ dan $\mathrm{R}$ yang semakin kecil, memperlihatkan hasil KF yang lebih baik dibandingkan dengan nilai $\mathrm{Q}$ dan $\mathrm{R}$ yang lebih besar. Semakin besar nilai $\mathrm{Q}$ dan $\mathrm{R}$, maka semakin lama hasil filter untuk menyesuaikan data. Nilai $Q$ dan $R$ yang cocok pada sensor suhu jenis DHT11 dan LM35 yaitu pada 1e-8 dan 1e-5.

\section{Ucapan terima kasih}

Seluruh penelitian ini dibiayai oleh DIPA Pusat Pengembangan Sumber Daya Kemetrologian Kementerian Perdagangan Tahun Anggaran 2018.

\section{DAFTAR PUSTAKA}

Aosong (Guangzhou) Electronics Co., "Temperature and Humidity Module. DHT11 Product Manual," lembar data DHT11.

Aosong (Guangzhou) Electronics Co., "Temperature and Humidity Module. AM2302 Product Manual," lembar data DHT22.

Arief Hendra Saptadi., "Perbandingan Akurasi Pengukuran Suhu dan Kelembaban Antara Sensor DHT11 dan DHT22 Studi Komparatif pada Platform
ATMEL AVR dan Arduino", Jurnal Infotel, Vol. 6, No. 2, Nop. 2014.

Kalman, R.E. (1960), “A New Approach to Linear Filtering and Prediction Problems", Transaction of the ADME-Journal of Basic Engineering, hal. 35-45

https://www.parallax.com/downloads/pl x-daq

ISO/IEC 17025:2017, ” General requirements for the competence of testing and calibratio laboratories 